\title{
RELATIONSHIP BETWEEN MORPHOLOGICAL DIFFER- ENTIATION AND EXTRACELLULAR ENZYME FORMATION IN ASPERGILLUS NIDULANS
}

\author{
YOSHINAO KOIDE, ${ }^{1}$ HIDEO YAMAGATA, AND SHIGEZO UDAKA \\ Department of Food Science and Technology, Faculty of Agriculture, \\ Nagoya University, Chikusa, Nagoya 464, Japan
}

(Received November 20, 1978)

\begin{abstract}
Intra- and extra-cellular activities of protease, nuclease, and invertase were examined with four newly isolated morphological mutants of Aspergillus nidulans. As far as the four mutants subjected to the investigation were concerned, extracellular activities of these enzymes were markedly changed. Some relationship between morphological mutation and extracellular enzyme formation was assumed and this assumption was supported genetically with two mutants which gave rise to wild-type revertants.
\end{abstract}

The fungi display relatively simple forms of differentiation and have been widely accepted as convenient organisms for studying morphogenesis. The Aspergilli display most common form of morphogenesis in the fungi, forming conidia on specialized aerial structures. Among the Aspergilli, Aspergillus nidulans seems to be one of the most suitable materials for the study of morphogenesis or differentiation, because it has been intensively investigated genetically.

In $A$. nidulans, Clutterbuck isolated many mutants altered in the development of conidial apparatus and analysed the background of the alteration genetically (1). ZONNEVELD reported studies on the correlation of the activity of $\alpha-1,3-$ glucanase, laminarinase, and amylase with conidiation (2). Despite these and many other observations on the process of conidiation (3), the biochemical basis of conidiation in A. nidulans is still not clear at present.

In order to obtain more informations on the biochemical changes during the conidiation, we newly isolated morphogenesis mutants of $A$. nidulans and examined their extracellular enzyme activities. The well-known relationship between the excretion of extracellular enzymes and structure of cell surface (4) as well as apparent changes of cell surface structure during the conidiation in the

1 Present address: Amano Pharmaceutical Co., 51 Nishi-shiroyashiki, Nishiharu-cho, Nishikasugai-gun, Aichi-ken 481, Japan. 
organism (l) prompted us to start this investigation.

\section{MATERIALS AND METHODS}

Strains. A. nidulans strain 0148 requiring biotin and $p$-aminobenzoic acid was kindly supplied by Dr. E. Forbes of the University of Glasgow.

Media. Minimal medium was that described by Dorn (5) with $1 \%$ glucose and $1.5 \%$ agar. Complete medium contained per liter; malt extract (Difco), $20 \mathrm{~g}$; polypeptone (Daigo), $1 \mathrm{~g}$; glucose, $20 \mathrm{~g}$; and vitamin solution (6), $5 \mathrm{ml}$. Limiting phosphate medium was that described by DORN (7).

Isolation of morphological mutants. Mutagenic treatment by ultraviolet ray was followed the method of PONTECORvo et al. (6). Ultraviolet ray-treated conidia of strain 0148 were plated on the complete medium plus sodium deoxycholate (8) to give about 100 colonies per plate and incubated at $37^{\circ}$ for 2 days. Among the resultant colonies, colorless colonies were picked up by visual selection and morphological mutants were searched under a microscope.

Culture conditions and preparation of extracellular or intracellular enzyme solutions. About $10^{6}$ conidia or $30 \mathrm{mg}$ wet weight of mycelia were inoculated in a series of $100-\mathrm{ml}$ Erlenmeyer flasks containing $20 \mathrm{ml}$ of the complete medium (for protease assay), limiting phosphate medium (for nuclease assay), or minimal medium (for invertase assay). Cultivations were continued until stationary phase of growth, at $37^{\circ}$ with shaking for protease formation and without shaking for nuclease or invertase formation. On each day, one flask was removed and mycelia were collected by filtration. The culture filtrate was used directly for the extracellular enzyme assay. Collected mycelia were washed with distilled water and homogenized with the same weight of quartz. Extracts were centrifuged at $18,000 \times g$ for $30 \mathrm{~min}$ at $4^{\circ}$ and the supernatant solution was used for the intracellular enzyme assay.

Enzyme assays. Protease activities were measured by a modified method of IsHIKAWA et al. (9), using $0.6 \%$ solution of casein in $0.05 \mathrm{~m}$ ammonium salt buffer $(\mathrm{pH} 8.0)$ as a substrate. After the incubation of $1 \mathrm{ml}$ of the substrate with $1 \mathrm{ml}$ of the enzyme solution, the reaction was stopped by addition of $3 \mathrm{ml}$ of $0.11 \mathrm{M}$ trichloroacetic acid containing $0.22 \mathrm{M}$ sodium acetate and $0.33 \mathrm{~m}$ acetic acid. Amino acid or peptide content of non-precipitated fraction was determined by the method of MACDONALD and CHEN (10). One unit of the activity was defined as the amount of the enzyme that hydrolyzed casein corresponding to $1 \mu \mathrm{mol}$ tyrosin per minute. Nuclease activity was measured according to IsHIKAWA et al. (9), using yeast RNA as a substrate. The $1.0 \mathrm{ml}$ reaction mixture contained $1.5 \mathrm{mg}$ RNA, $0.1 \mathrm{M}$ potassium phosphate buffer ( $\mathrm{pH}$ 6.0), 0.005 M ethylenediaminetetraacetic acid, and $0.2 \mathrm{ml}$ of the enzyme fraction. The reaction was started by the addition of substrate to the reaction mixture. Incubation was carried out at $37^{\circ}$ for $15 \mathrm{~min}$. The reaction was stopped by addition of $0.25 \mathrm{ml}$ of $25 \%$ per- 
chloric acid containing $0.75 \%$ uranyl acetate. The mixture was allowed to stand in an ice water for at least $10 \mathrm{~min}$ and was centrifuged at 3,000 rpm for $15 \mathrm{~min}$. Two-tenths $\mathrm{ml}$ of the supernatant was diluted with $5 \mathrm{ml}$ of water and the optical density at $260 \mathrm{~nm}$ was measured. One unit of the activity was defined as the amount of the enzyme producing a change of absorbance of 1.0 under the conditions employed. Invertase activity was measured as follows: A mixture of $1 \mathrm{ml}$ of the enzyme solution, $100 \mathrm{~mm}$ sucrose, $50 \mathrm{~mm}$ sodium acetate-acetic acid buffer ( $\mathrm{pH} 5.0)$, and $2 \mathrm{~mm}$ ethylenediaminetetraacetic acid was incubated at $30^{\circ}$ for $5 \mathrm{~min}$. Amount of reducing sugar was measured by the method of NoELTING et al. (11). One unit of the activity was defined as the amount of the enzyme producing $100 \mu \mathrm{g}$ of glucose from sucrose per minute.

\section{RESULTS}

\section{Morphological mutants isolated}

Sixty-six morphological mutants were isolated from the strain 0148 as described above. These mutants were classified into four groups according to the morphological characteristics; abnormal sterigma (group I), abnormal vesicles (group II), penicillus-like conidial heads (group III), and hyperformation of Hulle cells (group IV). Forms of typical mutants of each group are illustrated in Fig. 1. Mutant strains used for subsequent enzyme assay, M3, M5, M29, and M66, belonged to group II, I, IV, and III, respectively.

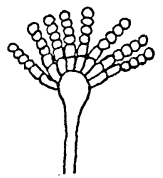

(A)

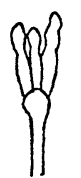

(B)

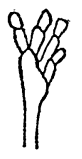

(C)

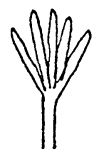

(D)

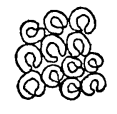

(E)

Fig. 1. Typical forms of morphological mutants (See text for explanation of each group of mutants).

(A) wild type; (B) mutant (group I); (C) mutant (group II); (D) mutant (group III); (E) mutant (group IV).

Although some of the mutants isolated were considerably different from the strain 0148 morphologically besides aconidiation, all these mutants showed requirements for biotin and $p$-aminobenzoic acid as 0148, and yielded recombinants when crossed with the master strain MSE (12). These data were taken as evidence that the mutants were derived from 0148 .

\section{Extracellular enzyme activities}

Several extracellular enzyme activities including protease, nuclease, invertase, amylase, and phosphatase were examined preliminarily in parental strain 0148 . Protease, nuclease, and invertase activities were detected and others were not 


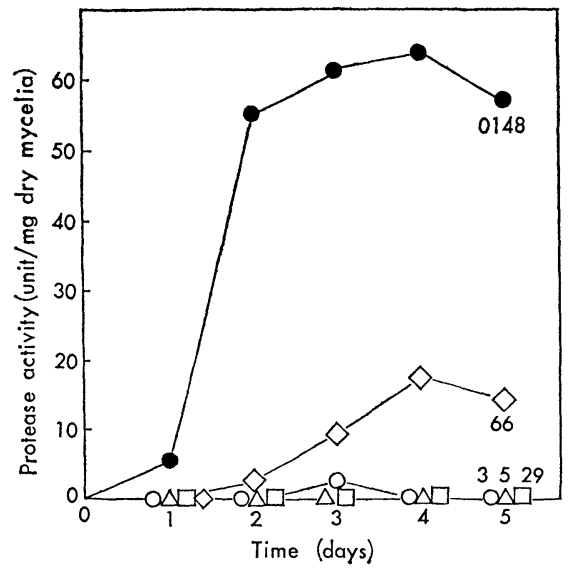

Fig. 2.

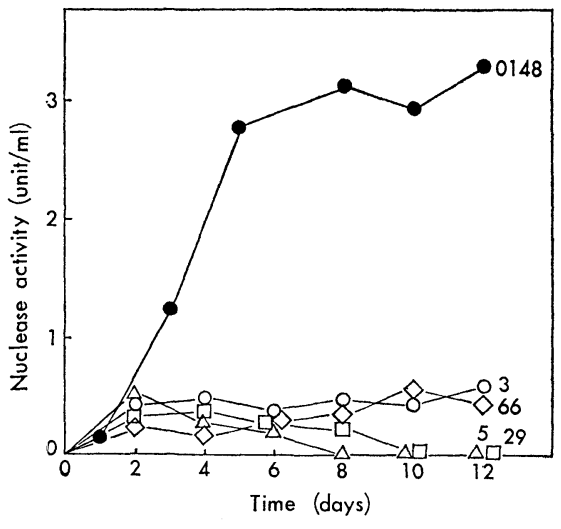

Fig. 3.

Fig. 2. Extracellular protease activities in the parent strain and mutant strains.

The parent strain $0148(\bullet)$ and mutant strains M3 (O), M5 ( $\triangle)$, M29 ( $\square)$, and M66 $(\diamond)$ were grown in complete medium.

Fig. 3. Extracellular nuclease activities in the parent strain and mutant strains.

The parent strain $0148(\bullet)$ and mutant strains M3 $(\bigcirc)$, M5 $(\triangle)$, M29 $(\square)$, and M66 $(\diamond)$ were grown in limiting phosphate medium.

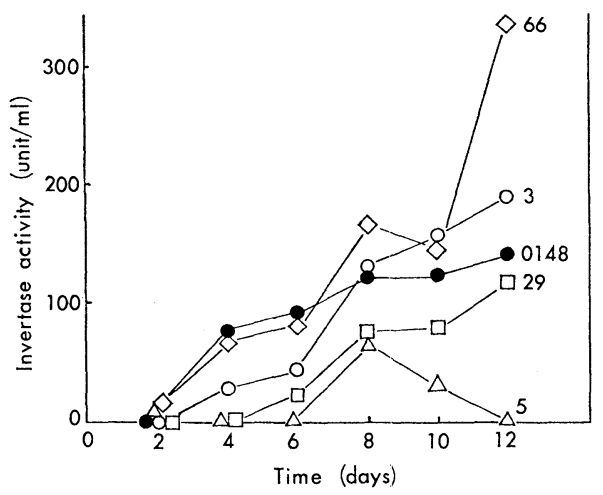

Fig. 4. Extracellular invertase activities in the parent strain and mutant strains.

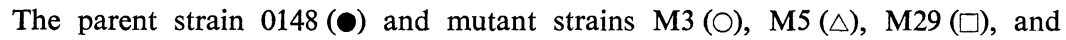
M66 ( $\diamond)$ were grown in minimal medium.

detected in our experimental conditions. Therefore, these three enzyme activities were compared among the parent strain 0148 and the morphological mutants M3, M5, M29, and M66. As shown in Fig. 2, extracellular protease activity apparently decreased in all four mutants throughout the 5 days of cultivation. Figure 3 shows that extracellular nuclease activities of all these mutants were 
Table 1. Extracellular nuclease activity (unit/mg dry mycelia).

\begin{tabular}{rrrrrr}
\hline \multirow{2}{*}{ Days } & \multicolumn{5}{c}{ Strain } \\
\cline { 2 - 6 } & 0148 & M3 & M5 & M29 & M66 \\
\hline 8 & 0.94 & 0.25 & $<0.05$ & 0.10 & 0.15 \\
10 & 0.85 & 0.15 & $<0.05$ & $<0.05$ & 0.15 \\
12 & 0.85 & 0.20 & $<0.05$ & $<0.05$ & 0.10 \\
\hline
\end{tabular}

Table 2. Extracellular invertase activity (unit/mg dry mycelia).

\begin{tabular}{rrrccc}
\hline \multirow{2}{*}{ Days } & \multicolumn{5}{c}{ Strain } \\
\cline { 2 - 6 } & 0148 & M3 & M5 & M29 & M66 \\
\hline 8 & 32 & 53 & 42 & 13 & 61 \\
10 & 34 & 63 & 21 & 16 & 61 \\
12 & 33 & 103 & $<5$ & 23 & 133 \\
\hline
\end{tabular}

about one-sixth or less of that of parent strain throughout the 12 days of cultivation. Thus, extracellular protease and nuclease activities markedly reduced in all of these mutants. As for extracellular invertase activity, mutants M3 and M66 showed higher activities than that of parent strain, while mutants M5 and M29 showed lower activities than that of parent strain (Fig. 4).

Since the above differences in the extracellular enzyme activities between mutants and parent strain were also demonstrated when the activities per dry weight of mycelia were compared, the difference seemed not to be due to the difference of growth rate between mutants and parent strain (Tables 1 and 2).

\section{Intracellular enzyme activities}

As indicated above, extracellular enzyme activities were apparently altered in our four morphological mutants. Two steps of reactions are generally involved in the formation of extracellular enzymes; synthesis of enzymes inside the cell and excretion of the enzymes into the medium. In order to determine which step was altered in our morphological mutants, intracellular activities of protease, nuclease, and invertase were measured and compared with the extracellular activities (Table 3). In mutants M3 and M66, intracellular protease activity was at about the same level as in the parent strain, while in mutants M5 and M29, the activity was not detected. Intracellular nuclease activity was detected in mutants M3, M29, and M66, while the activity was not detected in the parent strain and mutant M5. Intracellular invertase activities in the mutants were higher than the parent strain except for mutant M5 which showed neither intracellular nor extracellular invertase activity.

Table 3 also indicates that apparent changes of the extracellular enzyme activities in our morphological mutants which were shown in the previous section were reproducibly observed. 
Table 3. Extracellular and intracellular activities of enzymes. ${ }^{a}$

\begin{tabular}{|c|c|c|c|c|c|c|}
\hline \multirow{2}{*}{ Strain } & \multicolumn{2}{|c|}{ Protease } & \multicolumn{2}{|c|}{ Nuclease } & \multicolumn{2}{|c|}{ Invertase } \\
\hline & $\mathrm{Exo}^{b}$ & $\operatorname{In}^{c}$ & Exo & In & Exo & In \\
\hline 0148 & 29 & 488 & 1.50 & $<0.05$ & 11 & 65 \\
\hline M3 & $<1$ & 358 & 0.05 & 8.35 & 16 & 113 \\
\hline M5 & 6 & $<1$ & $<0.05$ & $<0.05$ & $<5$ & $<5$ \\
\hline M29 & $<1$ & $<1$ & 0.05 & 3.25 & 6 & 94 \\
\hline M66 & $<1$ & 766 & $<0.05$ & 1.60 & 32 & 67 \\
\hline
\end{tabular}

$a$ Mycelia were grown as described in MATERIALS AND METHODS. Extracellular and intracellular enzyme activities were determined at 4 days (protease), 8 days (nuclease), or 10 days (invertase) of cultivation.

$b$ Extracellular enzyme activities (unit/mg dry mycelia).

$c$ Intracellular enzyme activities (unit/mg of soluble proteins).

Genetic relationship between morphological mutations and extracellular enzyme activities

In order to confirm the relationship genetically, attempts were made to obtain revertants from the morphological mutants. Revertants which produced green conidia were obtained from mutant M5 spontaneously, and from mutant M29 through ultraviolet ray mutagenesis. These revertants were named R5 and R29, respectively. Both $\mathrm{R} 5$ and $\mathrm{R} 29$ required biotin and $p$-aminobenzoic acid for growth, indicating that they were derived from the morphological mutants. Table 4 shows the extracellular enzyme activities of R5 and R29. In revertant R5, extracellular nuclease and invertase activities were restored the same level as that of the parent strain. In revertant R29, only extracellular nuclease activity was restored to the same level as that of the parent.

It must be noted that although the genetic crosses were made between the morphological mutants and the strain MSE (12), which has at least one mutated locus on each of the eight linkage groups, none of the genetic markers of MSE showed linkage to the morphological mutations.

Table 4. Extracellular enzyme activity (unit/mg dry mycelia) ${ }^{a}$ of revertant strains.

\begin{tabular}{cccc}
\hline Strain & Protease & Nuclease & Invertase \\
\hline 0148 & 20 & 1.35 & 11 \\
M5 & $<1$ & $<0.05$ & $<5$ \\
M29 & $<1$ & $<0.05$ & 6 \\
R5 $^{b}$ & 3 & 1.35 & 11 \\
R29 $^{c}$ & $<1$ & 0.70 & 7 \\
\hline
\end{tabular}

$a$ Mycelia were grown as described in MATERIALS AND METHODS. Extracellular enzyme activities were determined at 4 days (protease), 8 days (nuclease), or 10 days (invertase) of incubation.

$b$ Wild-type revertant obtained from mutant M5.

c Wild-type revertant obtained from mutant M29. 


\section{DISCUSSION}

In all morphological mutants tested, the extracellular protease, nuclease, and invertase activities were shown to be affected. Assuming that formation of these extracellular enzymes consists of two steps, enzyme synthesis inside the cell and excretion of the enzyme into the medium, each mutant seems to have defects in the following steps; mutant M3, excretion of protease and nuclease; mutant M5, synthesis of protease, nuclease, and invertase; mutant M29, synthesis of protease and excretion of nuclease; and mutant 66 , excretion of protease and nuclease. In some cases where excretion seemed to be defective, intracellular enzyme activities increased (nuclease in mutants M3, M29, and M66, and protease in mutant M66), suggesting the accumulation of enzymes inside the cell. It must also be noted that extracellular invertase activities were increased in mutants M3 and M66. The possibility that some inhibiting material affected the activities of enzymes in our assay system was denied by the experiments where the mixture of the enzyme solution from parent strain and those from mutant strains was used (data not shown).

It seems difficult to assume that mutations responsible for the changes in extracellular enzyme activities were fortuitously accompanied with morphological mutation in all four mutants tested. Therefore, results reported in this paper probably indicate some relationship between morphogenesis and extracellular enzyme formation in $A$. nidulans. The relationship was apparently supported genetically about the formation of invertase in mutant M5 and the formation of nuclease in mutants M5 and M29 from which wild-type revertants were obtained.

Biological meaning of the relationship is not clear at present. Direct relation might be possible in that these extracellular enzymes were formed only at certain stages of conidiation. Indirect relation might also be possible as follows: Some kind of differentiation of cell surface which does not affect vegetative growth is required for the formation of extracellular enzymes and this differentiation of cell surface involves some process in common with differentiation towards conidiation.

The finding in this study is reminiscent of the phenomena found in bacteria that mutations known to block sporulation are pleiotropic, giving impairing effect on functions such as protease and antibiotic production, and sensitivity to surfaceactive antibiotics or phages (13).

We are very grateful to Drs. E. Forbes, A. J. Clutterbuck, and J. R. Kinghorn of the University of Glasgow for supplying $A$. nidulans strains and for useful discussions. We also thank Professor emeritus Y. Ikeda of the University of Tokyo for reading the manuscript and Amano Pharmaceutical Co. for supporting the investigation.

\section{REFERENCES}

I) A. J. Clutterbuck, Genetics, 63, 317 (1969).

2) B. J. M. ZonNeveld, J. Gen. Microbiol., 81, 445 (1974). 
3) J. E. Smith and J. G. Anderson, Symposia of the Society for General Microbiology, XXIII, Microbiol Differentiation (1973), p. 295.

4) A. R. GlenN, Annu. Rev. Microbiol., 30, 41 (1976).

5) G. L. DoRn, Genetics, 66, 267 (1970).

6) G. Pontecorvo, J. A. Roper, L. M. Hemmons, K. D. MacDonald, and A. W. J. Bufton, Adv. Genet., 5, 141 (1953).

7) G. DoRN, Genet. Res., 6, 13 (1965).

8) M. E. MacKintosh and R. H. Pritchard, Genet. Res., 4, 320 (1963).

9) T. Ishikawa, A. Toh-E, I. Uno, and K. Hasunuma, Genetics, 63, 75 (1969).

10) C. E. MacDonald, and L. L. Chen, Anal. Biochem., 10, 175 (1963).

11) G. Noelting, and P. Bennfeld, Helv. Chim. Acta, 31, 287 (1948).

12) K. S. MCCully, and E. Forbes, Genet. Res., 6, 352 (1965).

13) S. P. Brehm, S. P. StaAl, and J. A. НоCH, J. Bacteriol., 115, 1063 (1973). 